\title{
Special issue - conservation and management of sea cliffs
}

\author{
Pat Doody $^{1} \cdot$ Paul Rooney ${ }^{2}$
}

Published online: 27 October 2015

(C) Springer Science+Business Media Dordrecht 2015

\section{Introduction/background}

Coastal cliffs occur as a marked break in slope between the land and the sea. They may have sloping to vertical faces and form when slippage and/or coastal erosion take place. They have a range of geomorohological features depending on their resilience, structure and exposure to weathering and the action of the sea. In the 1970s and 1980s, the Nature Conservancy and later the Nature Conservancy Council (Governmental Agencies) began work to establish the status of sea cliff habitats around the United Kingdom. This special issue seeks to raise the profile of this important but neglected habitat in Europe.

\section{The situation in the UK}

Information on coastal cliffs in the UK at least, dates back to 1971, when the Nature Conservancy Coastal Habitat Team set up a sea cliff vegetation study group. This group recognising that there had been relatively little progress in surveying and evaluating this habitat produced a report, which provided a "working definition", a "technique for the collection of data" and "techniques for classifying vegetation". As part of the review of coastal habitats undertaken by the Nature Conservancy Council, Coastal Branch of the Chief Scientist

Pat Doody

pat.doody@ntlworld.com

Paul Rooney

rooneyp@hope.ac.uk

1 National Coastal Consultants, 5 Green Lane, Brampton, Huntingdon, Cambs. PE28 4RE, UK

2 Geography Department, Liverpool Hope University, Faculty of Science and Social Science, Hope Park, Liverpool L16 9JD, UK
Team in the 1980s, a preliminary review of the extent of sea cliff habitat in Great Britain was undertaken (Fig. 1).

During the 1990s, the Chief Scientist Directorate of the Nature Conservancy Council embarked on the survey of vegetation of Great Britain, which included maritime cliffs and slopes. As part of this review, the Coastal Branch funded surveys of a representative selection of sea cliff sites. These together with a three year programme of fieldwork around the coasts of Great Britain during the late 1980s early 1990s resulted in a "Sea Cliff Management Handbook" (Mitchley and Malloch 1991). This provides a summary of the ecology of the habitat with information on important management methods. Vegetation restoration where bracken and scrub dominate together with general weed control, grazing, small-scale burning and cutting management are all discussed. Information on the faunal component and major plant communities of sea-cliffs is also included.

Further surveys of maritime cliffs and slopes have been undertaken since then and provide detailed information on sites in England (Hill et al. 2001, 2006).

Common Standards Monitoring guidance for maritime cliff and slope habitats is also available http://jncc.defra.gov.uk/ pdf/CSM_coastal_cliff_slope.pdf for the UK but is already 10 years old (August 2004). The UK Biodiversity Action Plan (BAP) for Sea Cliff http://webarchive.nationalarchives. gov.uk/20110303145213/http:/ukbap.org.uk/UKPlans.aspx? $\mathrm{ID}=27$ is consigned to the National Archives web site. The UK Biodiversity Action Reporting System (BARS) National action plan for Maritime cliff and slopes states "there is now a dire need to carry out a national ecological survey of maritime cliffs covering both vegetation and other important features particularly any invertebrate interest. Without this baseline information, it will be very difficult to develop a proper targeted programme of restoration and re-creation and to gain any insight in whether or not we are making progress towards achieving BAP targets." 
Fig. 1 Distribution of coastal cliffs $>20$ m measurements in $\mathrm{km}$ based on 1:50,000 Ordnance Survey maps

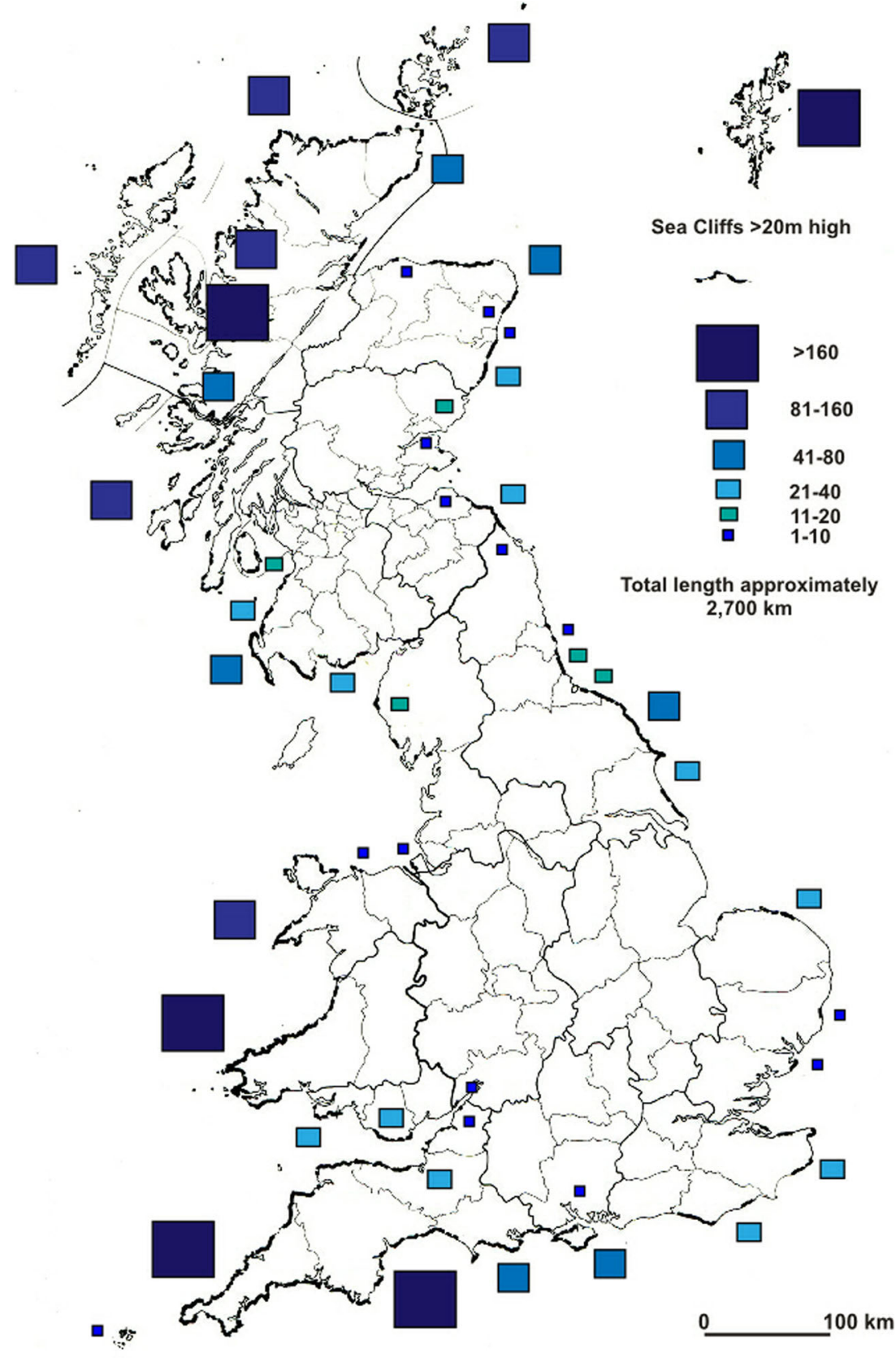

Area measurements based on 1:50000 os maps for each administrative unit in ha.
There are a number of published Local BAP's such as Devon http://www.devon.gov.uk/bapd-sea_cliff_and_slope. pdf (2004), Isle of Wight http://www.wildonwight.co.uk/ publications/haps/MCSHAP.pdf (2002), Gwynedd in Wales https://www.gwynedd.gov.uk/en/Council/DocumentsCouncil/Strategies-and-policies/Environment-and-planning/ Biodiversity/Habitat-Action-Plans/Maritime-Cliff-andSlopes-HAP.pdf (2004) and the Northumberland Biodiversity Action Plan http:/www.nwt.org.uk/sites/default/files/files/ Nland_Biodiversity_Action_Plan.pdf which includes a section on Maritime Cliffs and Slopes (latest version 2008).
A brief review of the Internet suggests there has been little work to establish how these plans are helping to conserve the wealth of nature conservation features on our sea cliffs.

\section{Coastal cliffs and lake bluffs symposium Tuesday 17th and Wednesday 18th September 2013, Llandudno, North Wales}

A seminar held in Llandudno, North Wales in September 2013 aimed to help raise the profile of this ecosystem amongst 
research workers, managers and conservationists. The papers in this special issue are derived from the presentations at the seminar. The dynamic nature of 'soft' rock sea cliffs helps create an important habitat for a range of specialist plants and animals and may have significant nature conservation interest. The relative stability of 'hard' rock coastal cliffs provides opportunities for a wider range of habitats than on rapidly eroding cliffs. The papers included in the special issue describe features relating to both 'soft' and 'hard' rock ecosystems.

Unconsolidated 'soft' rock material, such as glacial till may erode rapidly and even on gentler slopes, support only limited ephemeral vegetation. By contrast large-scale landslips, which remain stable for many years can support dense woodland. 'Hard' exposed, unyielding vertical cliffs, such as those made of granite, also support little vegetation, except in rock crevices. Where soils develop, however, a variety of vegetation types reflects the underlying geology and degree of exposure to salt spray and salt laden wind. Thus, sea cliffs support vegetation ranging from ephemeral communities of eroding soils to semi-stable para-maritime grassland, heathland and dense ancient woodland, together with their associated animals. Climatic effects are a distinct feature affecting cliffs in coastal locations. Halophytic plants survive in the face of exposure to sea spray or salt laden air. Wind-pruned trees and shrubs characterise other exposed locations. In some areas, oceanic effects may ameliorate the climate, influencing the vegetation some distance inland.

Vertical or near vertical 'hard' rock cliffs also provide nesting habitat for large seabird colonies, where freedom from predation and close proximity to marine feeding areas is important. In addition, the relative inaccessibility of steeper slopes makes them amongst the habitats least disturbed by human activity. Taken together, the interplay between geology, geomorphology and climate provide opportunities for the development of a biologically diverse habitat. However, despite this, by comparison with other coastal habitats, namely saltmarsh, sand dune and shingle (gravel) structures their ecology and conservation is less well known.

The first set of papers deals with 'soft' rock sea cliffs and Rees et al. discusses the range of habitats in England. Here there are a high proportion of unconsolidated sea cliffs in the UK. They form part of the range of variation of the Habitats Directive Annex I habitat 'vegetated sea cliffs of the Atlantic and Baltic coasts' (European Commission 2007). They are also probably of significance in a European context, yet the difficulties of mapping and describing this variable habitat means that their value is often under-estimated. The range of niches and the dynamic nature of the system, help to create a biologically diverse habitat. The paper describes the conservation of this habitat and explores the way evaluation of the impact of coast protection schemes takes place by reference to specific case studies.
Within this dynamic environment, erosion is a significant issue, especially when human assets are at risk. Often coastal protection schemes take precedence over the value for nature conservation. The paper by Moore provides an overview of the nature of erosion, the issues and administrative framework for the management of cliff instability in England and Wales. The lessons learnt from specific casework illustrate success stories as well as providing comparisons with best practice from across Europe.

The Holderness coast provides a specific example of the issues and actions on a 'soft' rock cliffed coastline. The coast is largely made up of Quaternary sediments, mainly glacial till, which form cliffs up to $38 \mathrm{~m}$ high. Hard defences are present in a number of locations along this coastline. The paper by Pye et al. highlights the way construction of coast protection works over the last 100 years has created 'hard points' and although cliff erosion continues, it does so at a diminishing rate. This has encouraged the formation of a series of 'stable' bays and a reduction in the alongshore rate of sediment movement southwards towards Spurn Point, threatening the integrity of this important coastal feature.

Howe describes the importance of coastal soft rock cliffs in UK for invertebrates. Here rich assemblages of species occur, some of which are restricted to this habitat. Recent analyses have identified 29 species confined to coastal soft rock cliffs, with a further 78 species having a high degree of dependence on them. Key habitats include bare sand or glacial till, extensive swards of leguminous and ruderal plants and hydrological features including seepages, pools and reedbeds. Unhindered dynamic processes such as erosion and cliff failure together with unimpeded drainage are critical to soft cliffs retaining their invertebrate interest.

The Heritage Coast site along the Dorset and East Devon is an area with internationally renowned coastal geomorphological landforms and processes. It is a naturally active coast with habitats ranging from vertical 'hard' cliffs to very active landslides, protected by both national and international conservation designations. A key feature of the Site is its dynamic nature, which provides a constant renewal of the visible geology and exposures of fossils. The paper by May describes its nature conservation value and the management plan established to control fossil collecting and conserve the site whilst allowing access, educational use and coast protection.

The second series of papers deals with 'hard' rock coasts. Here erosion often seems to be imperceptible. However, limited research into the recession of the 'harder rock' coastlines exposed to a highly energetic wave climate shows the extent to which erosion does occur. Airborne LiDAR (Light Detection and Ranging) data provided a way of gaining a quantitative understanding of cliff erosion along rocky coastline where recession rates are relatively low (c. $0.1 \mathrm{~m} \mathrm{yr}^{-1}$ ). The paper by Earlie et al. Shows how three-dimensional volumetric changes on the cliff face and linear rates of retreat can 
be reliably calculated from consecutive digital elevation models (DEMs) several years apart. The short-term retreat rates captured by this method can provide a representation of long-term change. Payo et al. provide an analysis of the way processes and feedback loops influence the rate of erosion. This in depth understanding will help determine future environmental and human intervention strategies.

Following a general introduction to sea cliff woodlands, the paper by Rhind highlights the value of this habitat with a detailed description of the steep, northwest facing slopes of the Lleyn Peninsula in Wales. Here a stand of ancient, relict oak woodland of considerable conservation interest appears to represent a remnant of a habitat much more wide spread before human influence. In Britain, there is only limited information on the few remaining examples of these distinctive coastal woodlands. This paper helps to redress this shortcoming and describes the vegetation and its affinity with the National Vegetation Classification woodland Quercus petraea-Betula pubescens-Oxalis acetosella woodland community (W11). Ratcliffe gives a detailed evaluation of conservation and management issues at another Welsh site, South Stack nature reserve on Anglesey.

Although not dealing solely with sea cliffs, the islands of the Outer Hebrides have extensive areas of inaccessible cliffs.
The paper by Angus describes the challenges of resource allocation and logistics for the small team of conservation staff based within the two Western Isles offices of Scottish Natural Heritage, Scotland's statutory nature conservation agency, in seeking to protect its nature conservation values.

It is hoped this special issue, will stimulate others both in the UK and more widely to investigate the ecology, conservation and management of this biologically diverse ecosystem.

\section{References}

European Commission, 2007. Interpretation Manual of European Union Habitats. EUR27, European Commission, DG Environment, Nature and biodiversity.

Hill CT, Ball JH, Dargie T, Tantram D, Boobyer G (2001) Maritime cliffs and slope inventory. Engl Nat Res Rep 426

Hill, C.T., Downes, R.H.E. \& Harfoot, A.J P. 2006. Maritime Cliff and Slope Inventory 2004/2005. Natural England Research Reports, No NERR003.

Mitchley, J. \& Malloch, A.J.C., 1991. Sea cliff management handbook for Great Britain. University of Lancaster and Joint Nature Conservation Committee in association with the National Trust, $125 \mathrm{pp}$. 